\title{
Borik Asit ve Boraks Pentahidrat Kristalleri için Kekleşmenin İncelenmesi
}

\author{
Sinan KUTLUAY ${ }^{1 *}$, M. Sait İZGí ${ }^{1}$, Ömer ŞAHİN ${ }^{1}$, A. Abdullah CEYHAN ${ }^{2}$ \\ ${ }^{I}$ Siirt Üniversitesi, Mühendislik Fakültesi, Kimya Mühendisliği Bölümü, Siirt \\ ${ }^{2}$ Konya Teknik Üniversitesi, Mühendislik ve Doğa Bilimleri Fakültesi, Kimya Mühendisliği Bölümü, Konya \\ (ORCID: 0000-0001-9493-918X) (ORCID: 0000-0003-3685-3219) \\ (ORCID: 0000-0003-4575-3762) (ORCID: 0000-0003-1592-5121)
}

\begin{abstract}
$\ddot{O} \mathbf{z}$
$\mathrm{Bu}$ çalışmada, CMSMPR (sürekli-karıştırmalı, sürekli-ürün çekmeli) tipi kristalizörde, saf ortamda üretilen borik asit $\left(\mathrm{H}_{3} \mathrm{BO}_{3}\right)$ ve boraks pentahidrat $\left(\mathrm{Na}_{2} \mathrm{~B}_{4} \mathrm{O}_{7} .5 \mathrm{H}_{2} \mathrm{O}\right)$ kristallerinin su alma yeteneği, kekleşme derecesi tayini ve mekanik dayanım, kekleşme, kırma testleri yapılmıştır. CMSMPR sisteminde üretilen hem $\mathrm{H}_{3} \mathrm{BO}_{3}$ hem de $\mathrm{Na}_{2} \mathrm{~B}_{4} \mathrm{O}_{7} .5 \mathrm{H}_{2} \mathrm{O}$ kristallerinin su alma yeteneği, kekleşme, aşınma derecelerinin yüksek olduğu ve bu kristallerin nemden oldukça etkilendiği ve bu nedenle habitinde bozulmalar meydana geldiği görülmüsşür. Ayrıca, kekleşme ve kırma testleri sonucunda belirlenen akışkanlık durumları değerlendirildiğinde ise $\mathrm{H}_{3} \mathrm{BO}_{3}$ kristallerinin kohezif (yapışan), $\mathrm{Na}_{2} \mathrm{~B}_{4} \mathrm{O}_{7} .5 \mathrm{H}_{2} \mathrm{O}$ kristallerinin ise çok kohezif olduğu tespit edilmiştir. Tüm bu sonuçlar esas alındığında, kekleşmeyi önlemek için $\mathrm{H}_{3} \mathrm{BO}_{3}$ ve $\mathrm{Na}_{2} \mathrm{~B}_{4} \mathrm{O}_{7} .5 \mathrm{H}_{2} \mathrm{O}$ kristallerinin yüksek nem oranlarına maruz kalmaması gerektiği görülmektedir.
\end{abstract}

Anahtar kelimeler: Boraks Pentahidrat $\left(\mathrm{Na}_{2} \mathrm{~B}_{4} \mathrm{O}_{7} .5 \mathrm{H}_{2} \mathrm{O}\right)$, Borik Asit $\left(\mathrm{H}_{3} \mathrm{BO}_{3}\right)$, Kristalin kekleşmesi.

\section{Investigation of Caking for Boric Acid and Borax Pentahydrate Crystals}

\begin{abstract}
In this study, the determination of hygroscopicity and the caking degree, and the tests of mechanical strength, caking, breaking of boric acid $\left(\mathrm{H}_{3} \mathrm{BO}_{3}\right)$ and borax pentahydrate $\left(\mathrm{Na}_{2} \mathrm{~B}_{4} \mathrm{O}_{7} .5 \mathrm{H}_{2} \mathrm{O}\right)$ crystals produced in pure medium in the CMSMPR (Continuous Mixed-Suspension, Mixed-Product Removal) type crystallizer were performed. Both the $\mathrm{H}_{3} \mathrm{BO}_{3}$ and $\mathrm{Na}_{2} \mathrm{~B}_{4} \mathrm{O}_{7} .5 \mathrm{H}_{2} \mathrm{O}$ crystals produced in the CMSMPR system were found to have high hygroscopicity, degrees of caking and attrition, and these crystals were highly influenced by moisture and thus deteriorated their habit. Furthermore, when the fluidity conditions determined as a result of caking and breaking tests were evaluated, it was found that $\mathrm{H}_{3} \mathrm{BO}_{3}$ crystals were cohesive and $\mathrm{Na}_{2} \mathrm{~B}_{4} \mathrm{O}_{7} .5 \mathrm{H}_{2} \mathrm{O}$ crystals were very cohesive. Based on these results, it is seen that $\mathrm{H}_{3} \mathrm{BO}_{3}$ and $\mathrm{Na}_{2} \mathrm{~B}_{4} \mathrm{O}_{7} .5 \mathrm{H}_{2} \mathrm{O}$ crystals should not be exposed to high humidity in order to avoid caking.
\end{abstract}

Keywords: Borax Pentahydrate $\left(\mathrm{Na}_{2} \mathrm{~B}_{4} \mathrm{O}_{7} .5 \mathrm{H}_{2} \mathrm{O}\right)$, Boric Acid $\left(\mathrm{H}_{3} \mathrm{BO}_{3}\right)$, Caking of crystal.

\section{Giriş}

Dünya bor rezervlerinin yaklaşı \% 73'nün Türkiye'de bulunması sebebiyle bor bileşikleri Türkiye için oldukça büyük önem arz etmektedir. Türkiye, dünyanın en zengin bor cevheri rezervlerine sahip olmakla birlikte, bor bileşiklerinin özellikle Avrupa piyasalarındaki en büyük satıcısı konumundadır [1]. Son yıllardaki çalışmalar, özellikle ülke ekonomisi göz önünde bulundurularak söz konusu cevherlerin ham olarak değil de piyasanın talebini karşılayacak özelliklere sahip çeşitli bor bileşikleri halinde ihracatını sağlamaya yönelik olarak yapılmaktadır. Dünya piyasasının kabul edebileceği kalite ve görünümde bor bileşikleri üretildiği takdirde, bu ihracatın başarılı bir şekilde gerçekleşmesi mümkün olabilir. Endüstriyel ve stratejik açıdan dünyadaki en önemli elementlerden biri olan bor, endüstrinin birçok alanında bor bileşikleri halinde kullanılmaktadır. Ülkemizin bor piyasasında hak ettiği yeri alabilmesi

\footnotetext{
"Sorumlu yazar: sinankutluay@ siirt.edu.tr,kutluays2012@gmail.com
}

Geliş Tarihi: 10.10.2019, Kabul Tarihi: 08.04.2020 
için bor bileşiklerinin, mevcut ve yeni üretim yöntemlerinin geliştirilmesine, proses verimliliği ve ürün kalitesinin arttırılmasına yönelik çalışmalar çok önemlidir. Önemli bor ürünlerinden olan borik asit $\left(\mathrm{H}_{3} \mathrm{BO}_{3}\right)$ ve boraks pentahidrat $\left(\mathrm{Na}_{2} \mathrm{~B}_{4} \mathrm{O}_{7} .5 \mathrm{H}_{2} \mathrm{O}\right)$ kristallerinin kristal habiti ve akışkanlık gibi kalite özellikleri ile ilgili yeterli bilgiye literatürde rastlanmamıştır. Bu nedenle, kristallerinin özellikleri ile ilgili bilgilerin tespit edilmesi oldukça önemlidir.

Kristalizasyon, temel kimyasal bileşiklerden özel kimyasallara kadar farklı maddelerin üretimi için uygulanan bir ayırma ve saflaştırma prosesidir [2]. Endüstriyel üretim prosesi sonucu elde edilen kristal ürünlerde görülen kekleşme işletmeler için büyük sorun etmektedir. Kekleşme, düşük partikül boyutundaki kristallerin aglomerasyonu sonucu daha büyük partikül boyutuna sahip bozuk şekilli kristallerin oluşumu olarak ifade edilmektedir [3, 4]. Endüstriyel olarak üretilen kristal ürünlerde karşılaşılan kekleşme sorunu, torbalarda veya tanklarda depolanması sürecinde meydana gelmektedir. Kristal ürünler bu süreçte serbest akıș özelliklerini kaybederek kekleșirler. Kristal ürünlerin nemden etkilenebilir olması, kekleşme sorununu meydana getiren en önemli özelliktir. Bu değerlendirmeler ışığında, kristal ürünlerin nemden etkilenebilir özelliklerinin düşük olması kekleşme sorununu azaltırken, tersi durumda ise kristal ürünler daha çok kekleşme eğilimi gösterirler [5]. Kitle halindeki yani ambalajsız tozlar zamanla dönüşümlere uğrayabilir ve bu, değişen çevresel ve mekanik koşullar tarafindan karmaşıklaştırılan dinamik bir prosestir. Kekleşme, kitle halinde bulunan madde içindeki sıcaklık ve su ya da madde ve çevresi arasındaki içerik profillerinden yoğun bir biçimde etkilenmektedir. $\mathrm{Bu}$ profiller anlaşılır ise, bunlar kekleşmenin oluşumu ve gücüne bağlanabilmektedir [6]. Bununla birlikte, çeşitli maddeler için kekleşmenin nedenleri farklılık gösterebilmektedir. Kristal boyutu, şekli, nem içeriği, ürünün altında depolandığı basınç ve depolama sürecinde sıcaklık ve nem değişimleri, gibi değişkenlerin tümü kristal ürünlerin kekleşmesine katkıda bulunabilir. Genellikle, kekleşme, kristal yüzeylerin nemli hale gelmesinden kaynaklanmaktadır. Kristal yüzeyleri birkaç yolla nemli hale gelebilir; ürün, yetersiz kalmış bir kurutma işleminden kalan bir miktar çözücü içerebilir, ya da nem dış kaynaklardan gelebilir [7]. Boraks kristallerinde meydana gelen kekleşme sorununu gidermek amacıyla yapılan çalışmalarda, birçok yöntem uygulanmıştır. Bu yöntemler arasında en çok kullanılanı ise boraks kristal yüzeylerinin iyi bölünmüş, nem-absorblayan ya da hidrofobik malzeme olan ya da organik bir yüzey aktif bir madde ile kaplanmasıdır. Boraks kristallerinin kekleşmesini engellemek amacıyla önerilen başka bir yöntem ise safsızlı̆̆ın giderilmesidir. Bu proseste, boraks kristallerinin pH'1 5.5'in altında olan bir asit çözeltisine maruz bırakılması sonucunda sürekli olarak serbest akış özelliğini koruduğu ifade edilmiştir [5]. Belirli bir habite ve homojen partikül boyut dağılımına sahip boraks kristallerinin üretilmesiyle birlikte karşılaşılan kekleşme sorununun önlenmesi için boraks dekahidratın özellikleri incelenmiştir [6]. Bu amaçla, farklı Ca içeriğine sahip boraks kristalleri üretilerek tek hücre sisteminde büyüme işlemine tabi tutulmuş ve kristal büyüme hızı ve büyüme kinetiği gibi faktörler incelenmiştir. Ayrıca Mg iyonunun ve anyonik ve katyonik flokülantların kristal şekli üzerine etkileri incelenmiştir. Daha sonra oleik asit, hekzanoik asit ve dekanoik asit varlığında kristal yapısında meydana gelen değişimler incelenmiş ve tek hücre sisteminde kristal büyütme prosesi oleik asit varlığında tekrarlanmıştır. Elde edilen sonuçlara göre, oleik asit varlığında kristal şeklinin (habitinin) diğer safsızlıklar ile karşılaştırıldığında daha iyi performans gösterdiği görülmüştür. Tek hücre sisteminde yapılan kristal büyütme prosesinde elde edilen sonuçlara göre ise safsızlıklar varlığında kristal büyüme hızının değişmediği görülmüştür. Johanson ve Paul [8] tarafından yapılan çalışmada, sıcaklık değiş̧iminin, yaygın olarak kullanılan tuz ve şeker de dahil olmak üzere bir dizi çözünür madde üzerindeki etkisi incelenmiştir. Numuneler, sabit sıcaklıkta 1.5 gün boyunca ağzı kapalı bir kapta saklandığında, tuz güçlü bir kek oluşturmuştur. Bu dönüşüm, dengeye ulaşılana kadar nemin yeniden dağılması ile ilişkilendirilmiştir. Tuz için sıcaklık döngüsü, döngü sayısıyla birlikte kekleşmenin kuvvetinde doğrusal bir artış göstermiştir. Bunun aksine, şeker, bir döngünün sonunda maksimum kekleşme gücüne ulaşmıştır. Benzer şekilde, Cleaver ve ark., [9] tarafindan yapılan çalışmada, $20^{\circ} \mathrm{C}$ ile $40^{\circ} \mathrm{C}$ arasında sıcaklık döngüsü sayısı ile $\mathrm{H}_{3} \mathrm{BO}_{3}$ kekleşme endeksinde sürekli bir artış olduğu ortaya konulmuştur.

$\mathrm{Bu}$ çalışmanın temel amacı, CMSMPR (sürekli-karıştırmalı, sürekli-ürün çekmeli) tipi kristalizörde, saf ortamda üretilen $\mathrm{H}_{3} \mathrm{BO}_{3}$ ve $\mathrm{Na}_{2} \mathrm{~B}_{4} \mathrm{O}_{7} .5 \mathrm{H}_{2} \mathrm{O}$ kristalleri için su alma yeteneği, kekleşme derecesi tayini ve mekanik dayanım, kekleşme, kırma testlerini gerçekleştirmektir. Çalışma kapsamında yapılan testler esas alındığında, kekleşme eğilimini önlemek için $\mathrm{H}_{3} \mathrm{BO}_{3}$ ve $\mathrm{Na}_{2} \mathrm{~B}_{4} \mathrm{O}_{7} .5 \mathrm{H}_{2} \mathrm{O}$ kristalleri için uygun kalite özellikleri belirlenmiş ve özellikle endüstriyel olarak üretilen bor ürün kristallerinde 
görülebilecek kekleşme eğiliminin tespiti ile ilgili önemli bir eksiklik araştırmacılara ve literatüre kazandırılmıştır.

\section{Materyal ve Metot}

$\mathrm{Bu}$ çalışma kapsamında kekleşme çalışmaları yapılan $\mathrm{H}_{3} \mathrm{BO}_{3}$ ve $\mathrm{Na}_{2} \mathrm{~B}_{4} \mathrm{O}_{7} .5 \mathrm{H}_{2} \mathrm{O}$ kristalleri sürekli beslemeli ve sürekli ürün çekmeli CMSMPR tipi bir kristalizörde üretilmiştir. CMSMPR sisteminde, kekleşme çalışmaları yürütülen $\mathrm{H}_{3} \mathrm{BO}_{3}$ kristallerinin elde edildiği kristalizasyon koşulları: 180 dakika kristalizörde kalma zamanı, $90-60^{\circ} \mathrm{C}$ verilen aşırı doygunluk, $250 \mathrm{rpm}$ karıştırma hızı, $80 \mathrm{~mL} / \mathrm{dk}$ besleme debisi, iken $\mathrm{Na}_{2} \mathrm{~B}_{4} \mathrm{O}_{7} .5 \mathrm{H}_{2} \mathrm{O}$ kristallerinin elde edildiği kristalizasyon koşulları ise: 120 dakika kristalizörde kalma zamanı, $90-65^{\circ} \mathrm{C}$ verilen aşırı doygunluk, $350 \mathrm{rpm}$ karıştırma hızı, $175 \mathrm{~mL} / \mathrm{dk}$ besleme debisidir. Ayrıca, CMSMPR tipi bir kristalizörde üretilen $\mathrm{H}_{3} \mathrm{BO}_{3}$ ve $\mathrm{Na}_{2} \mathrm{~B}_{4} \mathrm{O}_{7} .5 \mathrm{H}_{2} \mathrm{O}$ kristalleri fitrasyon yöntemiyle süspansiyondan ayrılmıştır. Elde edilen $\mathrm{H}_{3} \mathrm{BO}_{3}$ ve $\mathrm{Na}_{2} \mathrm{~B}_{4} \mathrm{O}_{7} .5 \mathrm{H}_{2} \mathrm{O}$ kristalleri etanol ile yıkandıktan sonra kurutulmuştur. Kekleşme çalışmaları yapılan $\mathrm{H}_{3} \mathrm{BO}_{3}$ kristallerinin partikül boyutu; $-500+425 \mu \mathrm{m}$, iken $\mathrm{Na}_{2} \mathrm{~B}_{4} \mathrm{O}_{7} .5 \mathrm{H}_{2} \mathrm{O}$ kristallerinin partikül boyutu; $-425+300 \mu \mathrm{m}$ ' dir.

CMSMPR tipi kristalizörde, saf ortamda üretilen $\mathrm{H}_{3} \mathrm{BO}_{3}$ ve $\mathrm{Na}_{2} \mathrm{~B}_{4} \mathrm{O}_{7} .5 \mathrm{H}_{2} \mathrm{O}$ kristallerinin kekleşme analizleri için üç farklı sistem kullanılmıştır. Kekleşme analizlerinde kullanılan sistemler ile yapılan çalışmaları şu şekilde sıralanabilir:

a) Kekleşme çalışmalarının ilk aşamasında, $\mathrm{H}_{3} \mathrm{BO}_{3}$ ve $\mathrm{Na}_{2} \mathrm{~B}_{4} \mathrm{O}_{7} .5 \mathrm{H}_{2} \mathrm{O}$ kristallerininin, su alma yeteneği ve kekleşme derecesinin hesaplanması ve karakterizasyonu,

b) İkinci aşamada, $\mathrm{H}_{3} \mathrm{BO}_{3}$ ve $\mathrm{Na}_{2} \mathrm{~B}_{4} \mathrm{O}_{7} .5 \mathrm{H}_{2} \mathrm{O}$ kristallerinin, mekanik mukavemet testine tabi tutularak hesaplanan aşınma derecesinin tespiti,

c) Son olarak ise $\mathrm{H}_{3} \mathrm{BO}_{3}$ ve $\mathrm{Na}_{2} \mathrm{~B}_{4} \mathrm{O}_{7} .5 \mathrm{H}_{2} \mathrm{O}$ kristallerinin, kekleşme ve kırma işlemleri için uygulanan basınçların oranı ile ifade edilen akıcılık doğruları ile kristal akıcılığının tayini çalışmaları yapılmıștır.

$\mathrm{Bu}$ analizleri gerçekleştirmek için aşağıdaki sistem ve eşitliklerden yararlanılmıştır.

\subsection{Su Alma Yeteneği ve Kekleşme Derecesi Analizleri}

$\mathrm{H}_{3} \mathrm{BO}_{3}$ ve $\mathrm{Na}_{2} \mathrm{~B}_{4} \mathrm{O}_{7} .5 \mathrm{H}_{2} \mathrm{O}$ kristallerinin, su alma yeteneği ve kekleşme derecesi tayini için kullanılan sistem Şekil 1'de verilmektedir. Bu sistemde, $5 \mathrm{~g}$ kristal numunesinin elek analizi yapılarak $500 \mu \mathrm{m}$ 'nin üstünde kalan $0.5 \mathrm{~g}$ kristal Gooch filtresine konulur. Numunenin \%100 neme doyurulması işlemi; $20^{\circ} \mathrm{C}$ 'deki çözünürlük değerine sahip olan $50 \mathrm{~mL}$ amonyun klorür $\left(\mathrm{NH}_{4} \mathrm{Cl}\right)$ çözeltisi kullanılarak oluşturulan nemin 3-400 mL/dk debideki hava ile Gooch filtresinde bulunan kristal numunesi üzerinden sürekli olarak geçirilmesi sonucunda sağlanır. Bu işlem esnasında, her 10 dakikada bir numunedeki ağırlık artışı kontrol edilir ve bu kontrol 30-40 dakikadan sonra her 20 dakikada bir yapılarak ağırlık farkının olmadığı denge anına kadar işlem devam eder. Numunedeki ağırlık artışı ilk başta normal olarak maksimum seviyeyi gösterir ve daha sonra hafifçe azalır ve sonunda sabit bir seviyeye ulaşır. Maksimuma ulaşıldığında analiz durdurulabilir. Normalde bu 4 saatten fazla sürmez. $\mathrm{Bu}$ işlem sonucunda, dengedeki numune ağırlığı belirlenerek su alma yeteneği Eşitlik 1 ile hesaplanır [10]. Bununla birlikte, nem çekme bakımından dengeye ulaşmış numunenin, $102 \pm 2^{\circ} \mathrm{C}^{\prime}$ deki etüvde 1 saat kurutulduktan sonra elek analizi ile $500 \mu$ m'nin üstündeki, ağırlığı belirlenir ve bu sonuç ile kekleşme derecesi Eşitlik 4 ile hesaplanır [11]. Kristal şeklindeki tüm numuneler az çok nem çekme özelliğine sahiptir. Nem çekme özelliği ile birlikte, numunenin içerdiği nem de önemlidir. Bir maddenin içerdiği nem; $5 \mathrm{~g}$ numune $87 \pm 2^{\circ} \mathrm{C}^{\prime}$ deki etüvde 6 saat boyunca kurutulduktan sonra Eşitlik 3 ile hesaplanır [12]. $\mathrm{Bu}$ eşitlikler yardımıyla hesaplanan, su alma yeteneği karakterizasyonu Tablo 1'e göre, kekleşme derecesi karakterizasyonu ise Tablo 2'ye göre belirlenir. 


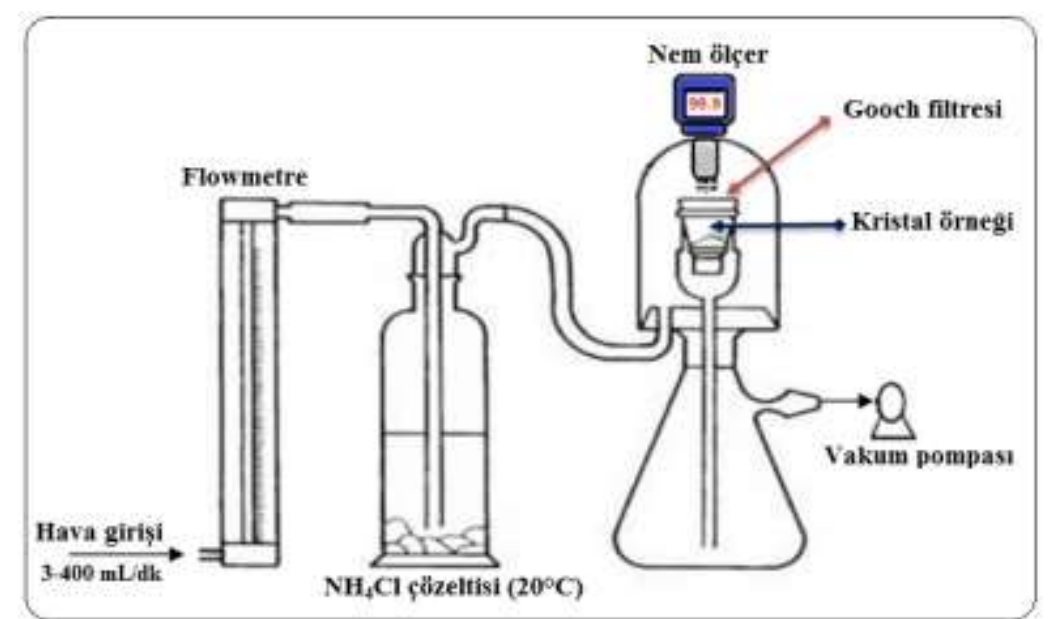

Şekil 1. Su alma yeteneği ve kekleşme derecesi tayini için kullanılan sistem [10]

Su alma yeteneği: Bir numunenin nem çekme özelliği, belirli koşullar altında nemli havaya maruz bırakıldıktan sonra dengedeki nem içeriğinin derecesidir.

$\%$ Su alma yeteneği $=\frac{\% \mathrm{WI}+\% \mathrm{FW}}{100+\% \mathrm{WI}} 100$

$\% \mathrm{WI}=\frac{\mathrm{c}-\mathrm{b}}{\mathrm{b}-\mathrm{a}} 100$

Burada;

$\mathrm{a}=$ Gooch filtresinin ağırlı̆ $1, \mathrm{~g}$

$\mathrm{b}=$ Gooch filtresinin ağırlığ $1+$ numune ağırlığı, $\mathrm{g}$

$\mathrm{c}=$ Gooch filtresinin ağırlığ $1+$ denge anındaki numune ağırlığı, $\mathrm{g}$

$\% \mathrm{FW}=\frac{\mathrm{b}-\mathrm{c}}{\mathrm{b}-\mathrm{a}} 100$

Burada;

$\mathrm{a}=$ Boş kap ağırlı̆̆

$\mathrm{b}=$ Boş kap ağırlı $\breve{g}_{1}+$ numune ağırlı̆̆ $1, \mathrm{~g}$

$\mathrm{c}=$ Boş kap ağırlığ $1+$ kurutulmuş numune ağırlığ $1, \mathrm{~g}$

\%WI: Belirli koşullar altında nemli havaya maruz bırakılan numunenin nem alma derecesidir.

$\% \mathrm{FW}$ : Numunenin içerdiği nemi ifade etmektedir.

$\%$ Kekleşme derecesi $=\frac{\mathrm{b}}{\mathrm{a}} 100$

Burada;

$\mathrm{a}=$ Kullanılan numune ağırlı̆̆ $1(500 \mu \mathrm{m}$ üstü), $\mathrm{g}$

$\mathrm{b}=$ Nem ve kurutma sonras1 elek üstünde kalan numune ağırlığı $(500 \mu \mathrm{m}$ üstü), $\mathrm{g}$

Tablo 1. Su alma yeteneği karakterizasyonu [10]

\begin{tabular}{lc}
\hline \multicolumn{2}{c}{ Su alma yeteneği } \\
\hline Nem çekme özelliği yok & $<\% 10$ \\
Nem çekme özelliği az & $\% 10.1-15$ \\
Nem çekme özelliği var & $\% 20.1-25$ \\
Nem çekme özelliği çok & $>\% 25$ \\
Nem çekme özelliği aşırı & \\
\hline
\end{tabular}


Tablo 2. Kekleşme derecesi karakterizasyonu [11]

\begin{tabular}{lc}
\hline \multicolumn{2}{c}{ Kekleşme derecesi } \\
\hline Kekleşme eğilimi olmayan toz & $<\% 10$ \\
Kekleşme eğilimi az olan toz & $\% 10.1-20$ \\
Kekleşme eğilimi çok olan toz & $\% 20.1-50$ \\
Kekleşme eğilimi çok olan toz & $>\% 50$ \\
Kekleşme eğilimi aşırı olan toz & $\% 100$ \\
\hline
\end{tabular}

\subsection{Mekanik Dayanım Testi ile Aşınma Derecesi Analizleri}

Kristal ürünlerin mekanik dayanımı, depolama ve taşınma sırasındaki aşınma ve kırılmalarla boyutunun küçülmesinin ölçüsüdür. Kristal ürünlerdeki mekanik dayanım, tüm boyut bölgelerinde partikül içeren karışımda yapıldığında ortalama olarak fikir edinmek mümkündür. Böyle bir ölçüm aşındırma derecesi tayini ile yapılabilmektedir. $\mathrm{H}_{3} \mathrm{BO}_{3}$ ve $\mathrm{Na}_{2} \mathrm{~B}_{4} \mathrm{O}_{7} .5 \mathrm{H}_{2} \mathrm{O}$ kristallerinin aşınma derecelerini tayin etmek amacıyla kullanılan sistem Şekil 2'de verilmektedir. Sistemde bulunan akışkanlaştırma kolonu $600 \mathrm{~mm}$ uzunluğunda ve $23 \mathrm{~mm}$ iç çapındadır. Akışkanlaştırma için gerekli olan hava kompresörden sağlanmaktadır. Havanın geçeceği delik $0.4 \mathrm{~mm}$ çapında olup, $90 \mathrm{~mm}$ çapında ve $3 \mathrm{~mm}$ kalınlığında pirinç bir plakanın merkezinde bulunmaktadır. Ayrıca, akışkanlaştırma esnasında kristal kaybını önlemek amacıyla kolonun üst kısmı, sadece havanın geçebileceği çaptaki $(0.4 \mathrm{~mm})$ bir kartuşla kapatılır. Deneye başlamadan önce, akışkanlaştırma için gerekli olan $7 \mathrm{~L} / \mathrm{dk}$ debideki hava akımı kolon üzerine yerleştirilen bir akış ölçer ile ayarlanır. Aşınma derecesi tayini için 50 g'lık iki numune alınır. Öncelikle ilk 50 g'lık numune, 10 dakika elenerek, $150 \mu$ m'nin altına geçen kısım tartılır. Diğer 50 g'llk numune ise, akışkanlaştırma kolonuna konularak kolonun üstü kartuşla kapatılır. Akışkanlaştırma için gerekli olan ve debisi daha önce ayarlanan hava verilerek, 10 dakika süre ile kristallerinin akışkanlaştırılması sağlanır. Bu sürenin sonunda, kolondan alınan numune 10 dakika eleme işlemine tabi tutulur ve $150 \mu$ m'nin altına geçen kısım tartılır. Her bir deneme için eleme süreleri ve hızları sabit tutulur. Bunun sonucunda aşınma derecesi aşağıdaki şekilde hesaplanır [13].

$\%$ Aşınma derecesi $=\frac{\mathrm{W}_{4}}{\mathrm{~W}_{3}} \cdot 100-\frac{\mathrm{W}_{2}}{\mathrm{~W}_{1}} \cdot 100$

Burada;

$\mathrm{W}_{1}=$ Sadece eleme işlemine tabi tutulan numune miktarı $(\mathrm{g})$

$\mathrm{w}_{2}=$ Eleme işlemi sonucunda $150 \mu \mathrm{m}$ 'nin altına geçen numune miktarı $(\mathrm{g})$

$\mathrm{w}_{3}=$ Aşınma testine tabi tutulan numune miktarı $(\mathrm{g})$

$\mathrm{w}_{4}=$ Aşınma testi sonucu $150 \mu \mathrm{m}$ 'nin altına geçen numune miktarı $(\mathrm{g})$.

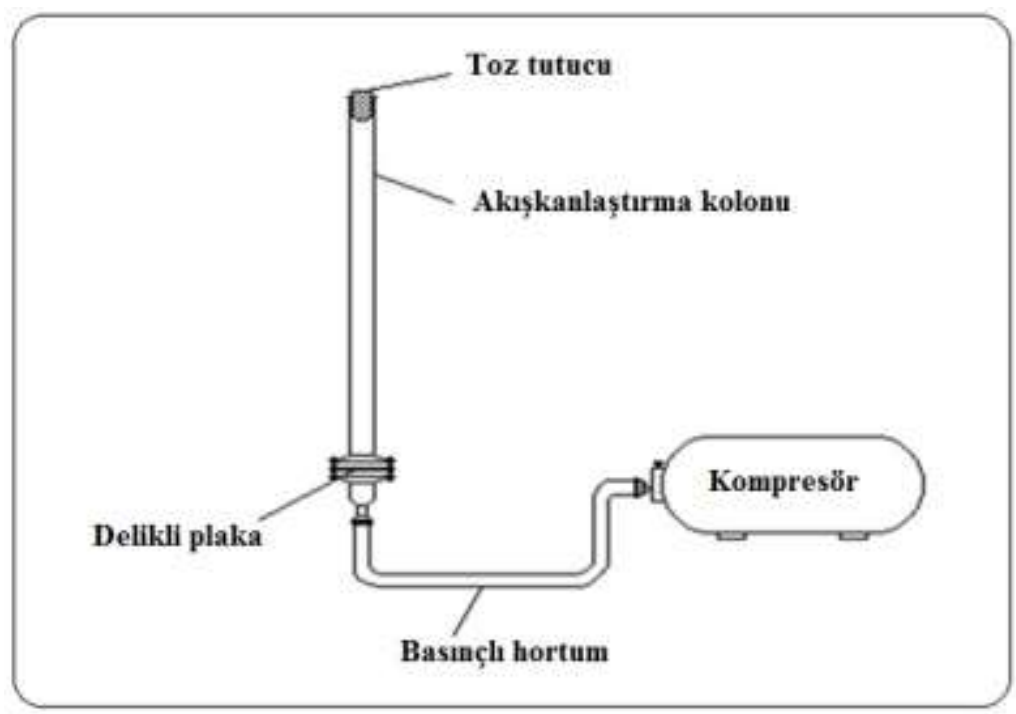

Şekil 2. Aşınma derecesi tayini için kullanılan sistemin şematik gösterimi 


\subsection{Kekleşme ve Kırma Testleri ile Kristal Akıcılığının Analizi}

$\mathrm{H}_{3} \mathrm{BO}_{3}$ ve $\mathrm{Na}_{2} \mathrm{~B}_{4} \mathrm{O}_{7} .5 \mathrm{H}_{2} \mathrm{O}$ kristallerininin basınç altında kekleşmesi ve oluşan kekin kırılması için kullanılan sistemin, şematik gösterimi Şekil 3'te, fotoğrafı ise Şekil 4'te verilmektedir. Şekil 3 ve Şekil 4a, ince taneli kohezif bir yığın katı ile dolu sürtünmesiz duvarlara sahip içi boş bir silindiri göstermektedir. İlk olarak, yığıı katı cisim (kristal) sıkıştırma basıncı $\left(\sigma_{1}\right)$ ile kekleştirilir. Daha sonra oyuk silindir çıkarılır ve numune kırılana kadar, giderek artan bir dikey basma gerilmesi ile silindirik yığın katı numuneye yükleme yapılır. Baskının sebep olduğu kırmaya, basınç dayanımı veya serbest akma dayanımı $\left(\sigma_{c}\right)$ denir. Serbest akma dayanımı genellikle sıkıştırma basıncı ile artar. Şekil 5'teki A eğrisi, sıkıştırma basıncından bağımsız olarak serbest akma dayanımının artışını göstermektedir. Ayrıca, Şekil 5'te, sınıflandırma aralıklarının sınırları düz doğrular gibi gösterilmektedir. Genellikle sıkıştırma basıncının serbest akma dayanımına oranı ile ifade edilen $\mathrm{ff}_{c}$, akışkanlığı sayısal olarak karakterize etmek için kullanılır [14]:

$f f_{c}=\frac{\sigma_{1}}{\sigma_{c}}$

Büyük $\mathrm{ff}_{\mathrm{c}}$ oranının olması durumunda yığın bir katı daha iyi akar. Genellikle Tablo 3’te verilen siniflandirma uygulanır.

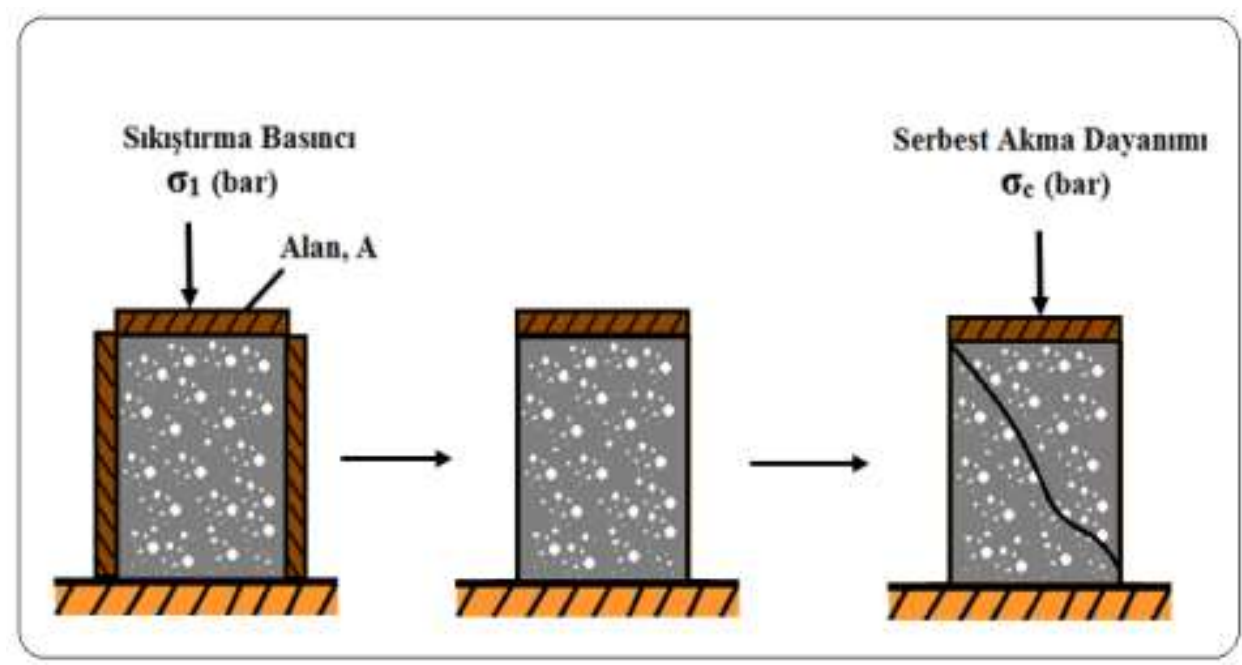

Şekil 3. Kristallerin kekleşmesi ve oluşan kekin kırılması için kullanılan sistemin şematik gösterimi

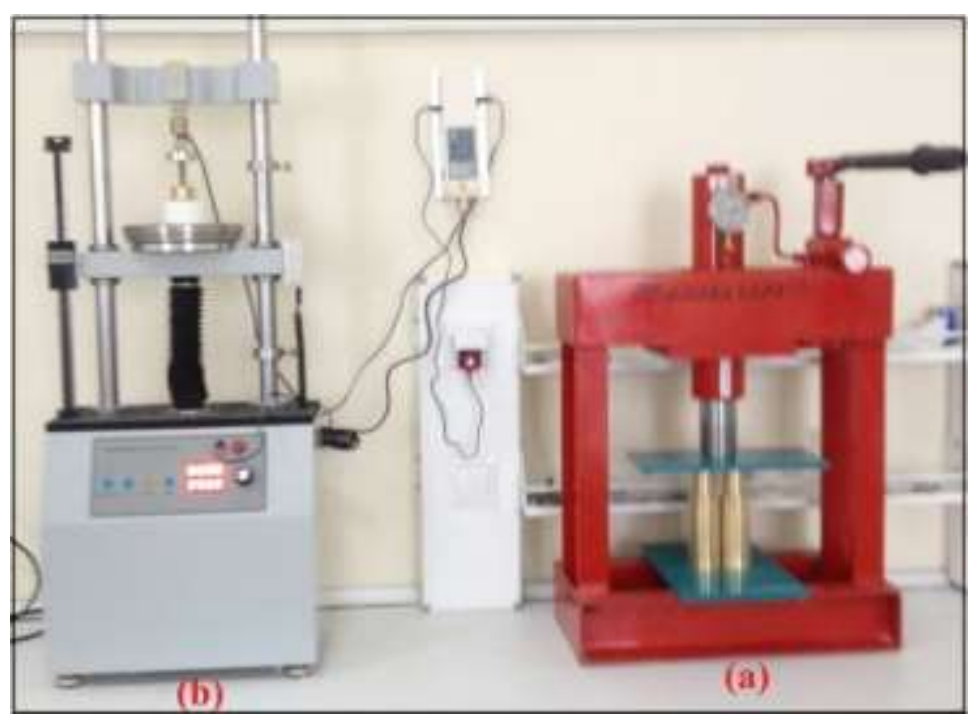

Şekil 4. Kristallerin basınç altında kekleştirilmesi ve oluşan kekin kırılması için kullanılan sistemlerin fotoğrafı (a:Numuneyi kekleştirme aparatı, b: Numuneyi kırma aparatı) 
Tablo 3. Akışkanlığın $\mathrm{ff}_{\mathrm{c}}$ ile sayısal olarak karakterizasyonu [14]

\begin{tabular}{ll}
\hline \multicolumn{2}{c}{ Akışkanlık durumu } \\
\hline Akmayan & $\mathrm{ff}_{\mathrm{c}}<1$ \\
Çok kohezif (akışkan olmayan için) & $1<\mathrm{ff}_{\mathrm{c}}<2$ \\
Kohezif (yapışan) & $2<\mathrm{ff}_{\mathrm{c}}<4$ \\
Kolay akan & $4<\mathrm{ff}_{\mathrm{c}}<10$ \\
Serbestçe akan & $10<\mathrm{ff}_{\mathrm{c}}$ \\
\hline
\end{tabular}

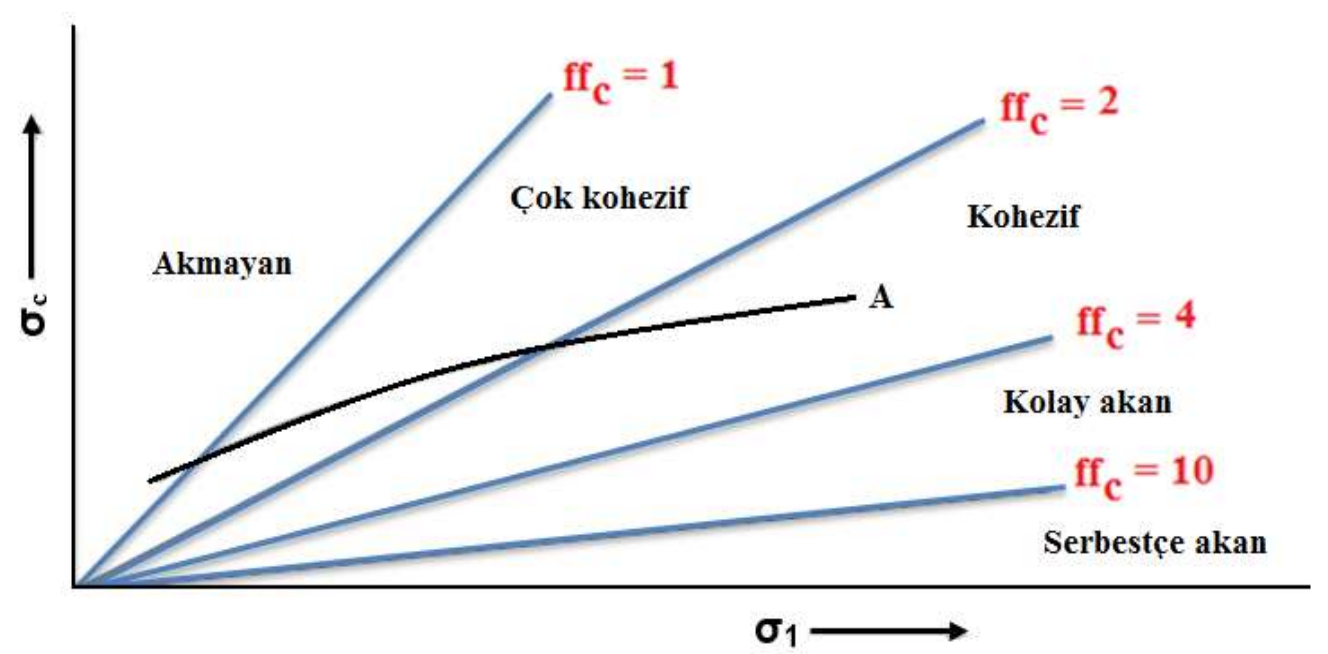

Şekil 5. Sıkıştırma basıncı üzerinde bağımsız serbest akma dayanımı; sabit akıcılık doğruları, $\mathrm{ff}_{\mathrm{c}}$

\section{Bulgular ve Tartışma}

CMSMPR sisteminde saf ortamda, üretilen $\mathrm{H}_{3} \mathrm{BO}_{3}$ ve $\mathrm{Na}_{2} \mathrm{~B}_{4} \mathrm{O}_{7} .5 \mathrm{H}_{2} \mathrm{O}$ kristallerinin su alma yeteneği ve kekleşme derecesi tayini ve mekanik dayanım, kekleştirme ve kırma testi çalışmaları, yukarıda açıklanan yöntemler esas alınarak yapılmıştır. Elde edilen sonuçlar aşağıda verilmiştir.

\section{1. $\mathrm{H}_{3} \mathrm{BO}_{3}$ ve $\mathrm{Na}_{2} \mathrm{~B}_{4} \mathrm{O}_{7.5} \mathrm{H}_{2} \mathrm{O}$ Kristallerinin $\mathrm{Su}$ Alma Yeteneği ve Kekleşme Derecesi Analiz Sonuçları}

$\mathrm{H}_{3} \mathrm{BO}_{3}$ ve $\mathrm{Na}_{2} \mathrm{~B}_{4} \mathrm{O}_{7} .5 \mathrm{H}_{2} \mathrm{O}$ kristallerinin, su alma yeteneği ve kekleşme derecesi sonuçları Tablo 4 'te verilmiştir. Tablo 4'te görüldügü üzere, saf ortamda üretilen $\mathrm{H}_{3} \mathrm{BO}_{3}$ ve $\mathrm{Na}_{2} \mathrm{~B}_{4} \mathrm{O}_{7} .5 \mathrm{H}_{2} \mathrm{O}$ kristallerinin hem su alma yeteneği hem de kekleşme derecesi sonuçları yüksek olmakla birlikte $\mathrm{Na}_{2} \mathrm{~B}_{4} \mathrm{O}_{7} .5 \mathrm{H}_{2} \mathrm{O}$ kristallerinin su alma yeteneği ve kekleşme derecesi sonuçlarının çok daha yüksek olduğu görülmektedir. Dolayısıyla, saf $\mathrm{H}_{3} \mathrm{BO}_{3}$ ve $\mathrm{Na}_{2} \mathrm{~B}_{4} \mathrm{O}_{7} .5 \mathrm{H}_{2} \mathrm{O}$ kristallerinin, nem çekme özelliği ile beraber kekleşme eğiliminin de olduğu görülmüştür. Bununla birlikte, $\mathrm{Na}_{2} \mathrm{~B}_{4} \mathrm{O}_{7} .5 \mathrm{H}_{2} \mathrm{O}$ kristallerinin, nem çekme özelliği ve kekleşme eğiliminin daha yüksek olduğu açıktır.

Tablo 4. $\mathrm{H}_{3} \mathrm{BO}_{3}$ ve $\mathrm{Na}_{2} \mathrm{~B}_{4} \mathrm{O}_{7} .5 \mathrm{H}_{2} \mathrm{O}$ kristallerinin su alma yeteneği ve kekleşme derecesi sonuçları

\begin{tabular}{ccccc}
\hline Maddeler & Su alma yeteneği & $\%$ & Kekleşme derecesi & $\%$ \\
\hline $\mathrm{H}_{3} \mathrm{BO}_{3}$ & Nem çekme özelliği az & 10.82 & Kekleşme eğilimi az & 16.03 \\
$\mathrm{Na}_{2} \mathrm{~B}_{4} \mathrm{O}_{7 .} .5 \mathrm{H}_{2} \mathrm{O}$ & Nem çekme özelliği çok & 23.45 & Kekleşme eğilimi çok & 28.64 \\
\hline
\end{tabular}

CMSMPR sistemde üretilen $\mathrm{H}_{3} \mathrm{BO}_{3}$ kristallerinin habitinin nemden nasıl etkilendiğini belirlemek için çalışmalar yürütülmüş̧ür. $\mathrm{Bu}$ kapsamda, su alma yeteneği işlemine tabi tutulan ve kekleşme derecesi tayini için kurutulan $\mathrm{H}_{3} \mathrm{BO}_{3}$ ve $\mathrm{Na}_{2} \mathrm{~B}_{4} \mathrm{O}_{7} .5 \mathrm{H}_{2} \mathrm{O}$ kristallerinin mikroskop ile belirlenen kekleşme öncesi ve sonrası görüntülerine ait sonuçlar Şekil 6'da verilmiştir. Şekil 6'da verilen mikroskop görüntülerinin incelenmesinde, hem $\mathrm{H}_{3} \mathrm{BO}_{3}$ hem de $\mathrm{Na}_{2} \mathrm{~B}_{4} \mathrm{O}_{7} .5 \mathrm{H}_{2} \mathrm{O}$ kristallerinin nemden etkilendiği ve habitinde bozulmalar meydana geldiği görülmüştür. Bunun yanı sıra, $\mathrm{Na}_{2} \mathrm{~B}_{4} \mathrm{O}_{7} .5 \mathrm{H}_{2} \mathrm{O}$ 
kristallerinin $\mathrm{H}_{3} \mathrm{BO}_{3}$ kristalleri ile kıyaslandığında, habitinde daha fazla bozulmalar meydana geldiği söylenebilir. Bu sonuç, söz konusu kristallerin nemli ortamlarda taşımması sırasında daha fazla kekleşebileceğini göstermektedir.

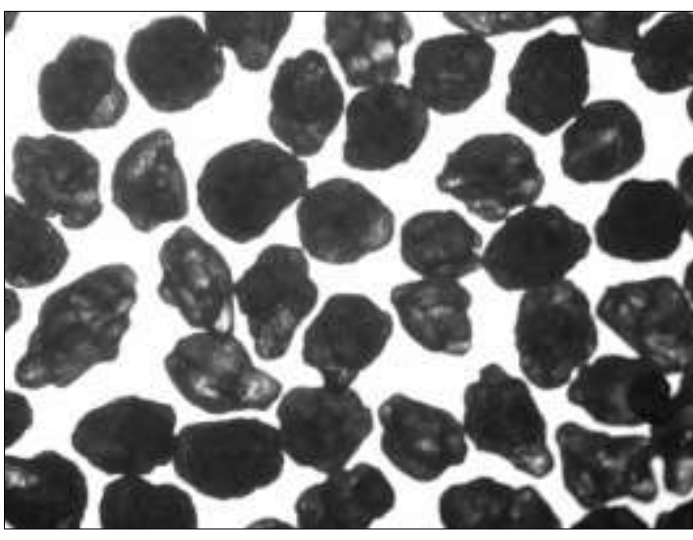

(a)

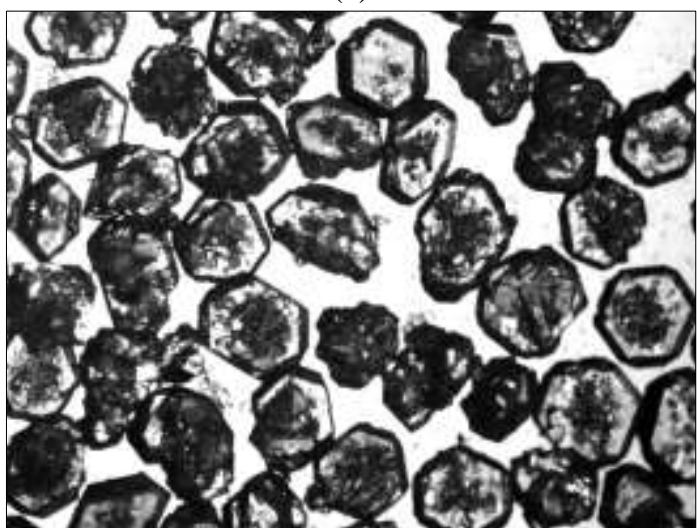

(c)

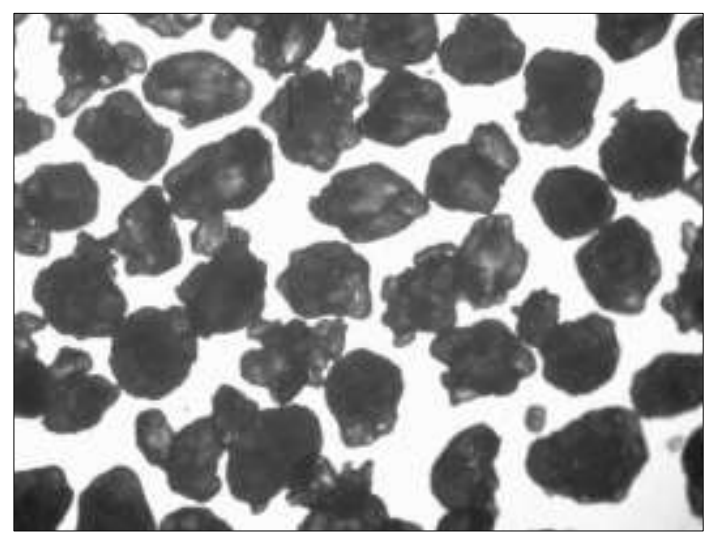

(b)

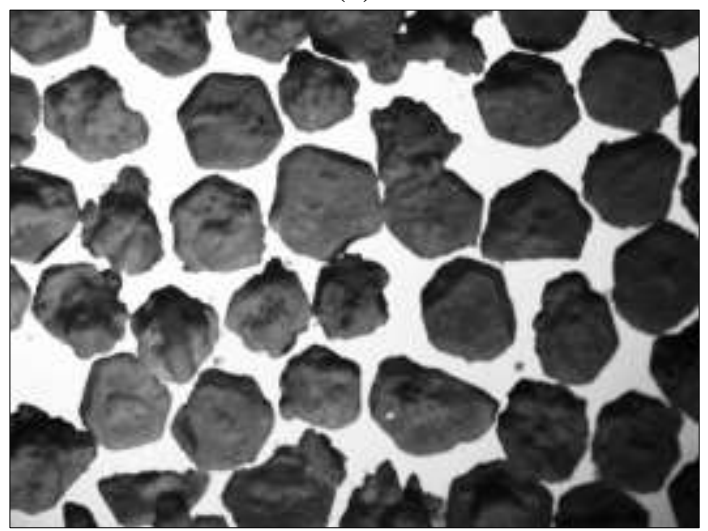

(d)

Şekil 6. CMSMPR sisteminde saf ortamda elde edilen, $\mathrm{H}_{3} \mathrm{BO}_{3}$ kristallerinin kekleşme (a) öncesi, (b) sonrası ve $\mathrm{Na}_{2} \mathrm{~B}_{4} \mathrm{O}_{7} .5 \mathrm{H}_{2} \mathrm{O}$ kristallerinin kekleşme (c) öncesi, (d) sonrası mikroskop görüntüleri

\section{2. $\mathrm{H}_{3} \mathrm{BO}_{3}$ ve $\mathrm{Na}_{2} \mathrm{~B}_{4} \mathrm{O}_{7} .5 \mathrm{H}_{2} \mathrm{O}$ Kristallerinin Mekanik Dayanım Testi Sonuçları}

Kristal ürünlerin mekanik dayanımı, depolama ve taşınma sırasındaki aşınma ve kırılmalarla boyutunun küçülmesinin ölçüsüdür. Kristal ürünlerdeki mekanik dayanım, tüm boyut bölgelerinde partikül içeren karışımda yapıldığında ortalama olarak fikir edinmek mümkündür. Böyle bir ölçüm aşındırma derecesi tayini ile yapılabilmektedir. Bu amaçla, bu çalışma kapsamında CMSMPR sisteminde saf ortamda üretilen $\mathrm{H}_{3} \mathrm{BO}_{3}$ ve $\mathrm{Na}_{2} \mathrm{~B}_{4} \mathrm{O}_{7} .5 \mathrm{H}_{2} \mathrm{O}$ kristallerinin aşınma derecelerini belirlemek için çalışmalar yürütülmüş olup elde edilen sonuçlar Tablo 5'te verilmiştir. Tablo 5 'te görüldüğü üzere, saf ortamda üretilen $\mathrm{H}_{3} \mathrm{BO}_{3}$ kristallerinin $\mathrm{Na}_{2} \mathrm{~B}_{4} \mathrm{O}_{7} .5 \mathrm{H}_{2} \mathrm{O}$ kristallerine nazaran aşınma derecelerinin daha yüksek olduğu görülmektedir.

Tablo 5. $\mathrm{H}_{3} \mathrm{BO}_{3}$ ve $\mathrm{Na}_{2} \mathrm{~B}_{4} \mathrm{O}_{7} .5 \mathrm{H}_{2} \mathrm{O}$ kristallerinin aşınma derecesi sonuçları

\begin{tabular}{cc}
\hline Maddeler & Aşınma derecesi (\%) \\
\hline $\mathrm{H}_{3} \mathrm{BO}_{3}$ & 2.482 \\
$\mathrm{Na}_{2} \mathrm{~B}_{4} \mathrm{O}_{7} .5 \mathrm{H}_{2} \mathrm{O}$ & 0.786 \\
\hline
\end{tabular}

\section{3. $\mathrm{H}_{3} \mathrm{BO}_{3}$ Kristallerinin Kekleşme ve Kırma Testi Sonuçları}

CMSMPR tipi kristalizörde üretilen saf $\mathrm{H}_{3} \mathrm{BO}_{3}$ kristallerinin serbest akma dayanımına, zamanın etkisini belirlemek için farklı zamanlarda $\left(1,2,3,12\right.$ ve 24 saat) 60 bar $\left(\sigma_{1}\right)$ sabit sıkıştırma basıncı uygulanmış olup elde edilen sonuçlar Şekil 7'de verilmiştir. Şekil 7'de görüldügüü üzere, 60 bar sabit sıkıştırma basıncı uygulamasında 3 saatten sonra serbest akma dayanımı fazla değişmemiştir. Sonuç olarak, 3, 12, 
24 saat ve 60 bar sıkıştırma basıncında elde edilen serbest akma dayanımı sonuçlarının hemen hemen aynı olduğu görülmektedir. Bu sonuç esas alınarak, çalışmanın bundan sonraki kısımlarında sıkıştırma süresi 3 saat olarak alınmıştır. Akışkanlığı sayısal olarak karakterize etmek için kullanılan, spesifik bir yığın kristalin sıkıştırma basıncının $\left(\sigma_{1}\right)$ serbest akma dayanımına $\left(\sigma_{\mathrm{c}}\right)$ oranı ile ifade edilen $\mathrm{ff}_{\mathrm{c}}$ sıkıştırma basıncı ile değişmektedir. Sabit sıkıştırma süresinde (3 saat), sıkıştırma basıncının $\mathrm{ff}_{\mathrm{c}}$ 'ye etkisini incelemek için 40, 50, 60 ve 70 bar basınçta çalışmalar yapılmış olup elde edilen sonuçlar Tablo 6'da verilmiştir. CMSMPR sisteminde üretilen saf $\mathrm{H}_{3} \mathrm{BO}_{3}$ kristalleri için $\mathrm{ff}_{\mathrm{c}}$ karakterizasyonu $\left(\mathbf{2}<\mathbf{f} \mathbf{f}_{\mathrm{c}}<\mathbf{4}\right)$ Şekil 8 'de gösterilmiştir. Buna göre, $\mathrm{H}_{3} \mathrm{BO}_{3}$ kristallerinin $\mathrm{ff}_{\mathrm{c}}$ aralığının sıkıştırma basıncı ile fazla değişmediği ve söz konusu kristallerin kohezif (yapışan) yapıya sahip olduğu anlaşılmaktadır. Bu yüzden çalışmanın bundan sonraki kısımlarında sıkıştırma basıncı 60 bar olarak alınmıştır.

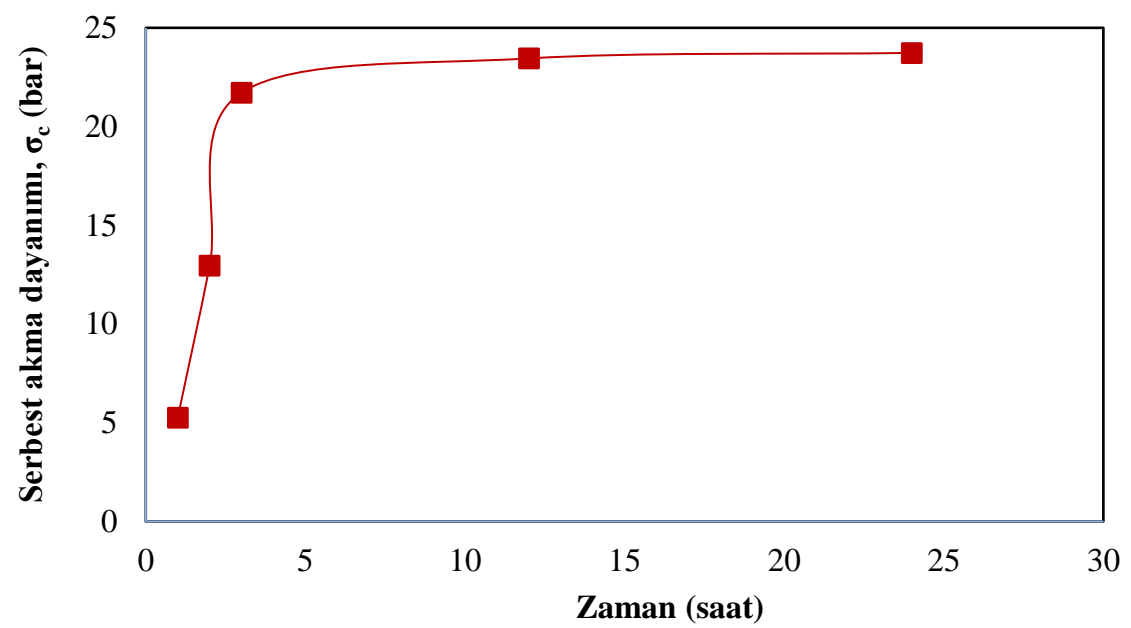

Şekil 7. CMSMPR tipi kristalizörde saf ortamda, üretilen $\mathrm{H}_{3} \mathrm{BO}_{3}$ kristallerine 60 bar sıkıştırma basıncı $\left(\sigma_{1}\right)$ uygulanması durumunda farklı zamanlar için serbest akma dayanımının değişimi

Tablo 6. $\mathrm{H}_{3} \mathrm{BO}_{3}$ kristalleri için sıkıştırma basıncının serbest akma basıncına oranı olan sabit akıcılık doğrusu (ff $)$ sonuçları

\begin{tabular}{ccc}
\hline $\begin{array}{c}\text { S1kıştırma basınc1, } \\
\sigma_{1}(\text { bar })\end{array}$ & $\begin{array}{c}\text { Serbest akma dayanımı, } \\
\sigma_{\mathrm{c}}(\text { bar })\end{array}$ & $\begin{array}{c}\mathrm{ff}_{\mathrm{c}} \\
\left(\sigma_{1} / \sigma_{\mathrm{c}}\right)\end{array}$ \\
\hline 0 & 0 & 0 \\
30 & 10.561 & 2.841 \\
40 & 13.995 & 2.858 \\
50 & 17.456 & 2.864 \\
60 & 21.308 & 2.816 \\
70 & 24.528 & 2.854 \\
\hline
\end{tabular}

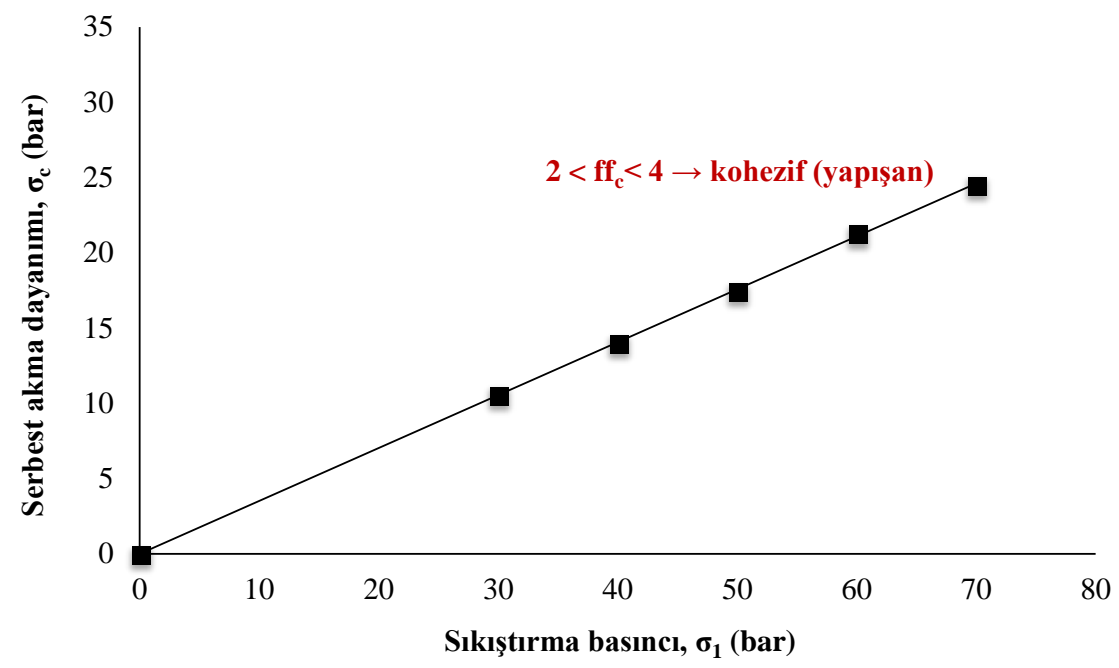

Şekil 8. Saf ortamda, üretilen $\mathrm{H}_{3} \mathrm{BO}_{3}$ kristallerinin sabit akıcıllk doğrusu, $\mathrm{ff}_{\mathrm{c}}$ 


\section{4. $\mathrm{Na}_{2} \mathrm{~B}_{4} \mathrm{O}_{7.5} \mathrm{H}_{2} \mathrm{O}$ Kristallerinin Kekleşme ve Kırma Testi Sonuçları}

CMSMPR tipi kristalizörde elde edilen saf $\mathrm{Na}_{2} \mathrm{~B}_{4} \mathrm{O}_{7} .5 \mathrm{H}_{2} \mathrm{O}$ kristallerinin serbest akma dayanımına, zamanın etkisini belirlemek için farklı zamanlarda (1, 2, 3, 12 ve 24 saat) 50 bar sabit sıkıştırma basıncı $\left(\sigma_{1}\right)$ uygulanmış olup elde edilen sonuçlar Şekil 9'da verilmiştir. Şekil 9'da görüldügü üzere, 50 bar sabit sıkıştırma basıncı uygulamasında, 3 saatten sonra serbest akma dayanımı fazla değişmemiştir. Sonuç olarak, 3, 12, 24 saat ve 50 bar sıkıştırma basıncında elde edilen serbest akma dayanımı sonuçlarının hemen hemen aynı olduğu görülmektedir. Bu sonuç esas alınarak, çalışmanın bundan sonraki kısımlarında sıkıştırma süresi 3 saat olarak alınmıştır. Akışkanlığı sayısal olarak karakterize etmek için kullanılan, spesifik bir yığın kristalin sıkıştırma basıncının $\left(\sigma_{1}\right)$ serbest akma dayanımına $\left(\sigma_{c}\right)$ oranı ile ifade edilen $\mathrm{ff}_{\mathcal{c}}$, sıkıştırma basıncı ile değişir. Sabit sıkıştırma süresinde (3 saat), sıkıştırma basıncının $\mathrm{ff}_{c}$ 'ye etkisini incelemek için 30, 40, 50, 60 ve 70 bar basınçta çalışmalar yapılmış olup elde edilen sonuçlar Tablo 7'de verilmiştir. CMSMPR sisteminde üretilen saf $\mathrm{Na}_{2} \mathrm{~B}_{4} \mathrm{O}_{7} .5 \mathrm{H}_{2} \mathrm{O}$ kristallerinin $\mathrm{ff}_{\mathrm{c}}$ karakterizasyonu sonuçları ise $\left(\mathbf{1}<\mathbf{f f}_{\mathbf{c}}<\mathbf{2}\right)$ Şekil 10 'da verilmiştir. Tablo 7 ve Şekil 9'da verilen sonuçlar incelendiğinde, saf ortamda üretilen $\mathrm{Na}_{2} \mathrm{~B}_{4} \mathrm{O}_{7} .5 \mathrm{H}_{2} \mathrm{O}$ kristallerinin $\mathrm{ff}_{\mathrm{c}}$ aralığının sıkıştırma basıncı ile fazla değişmediği ve söz konusu kristallerin çok kohezif (yapışan) yapıya sahip olduğu anlaşılmaktadır. Bu yüzden çalışmanın bundan sonraki kısımlarında sıkıştırma basıncı 50 bar olarak alınmıştır.

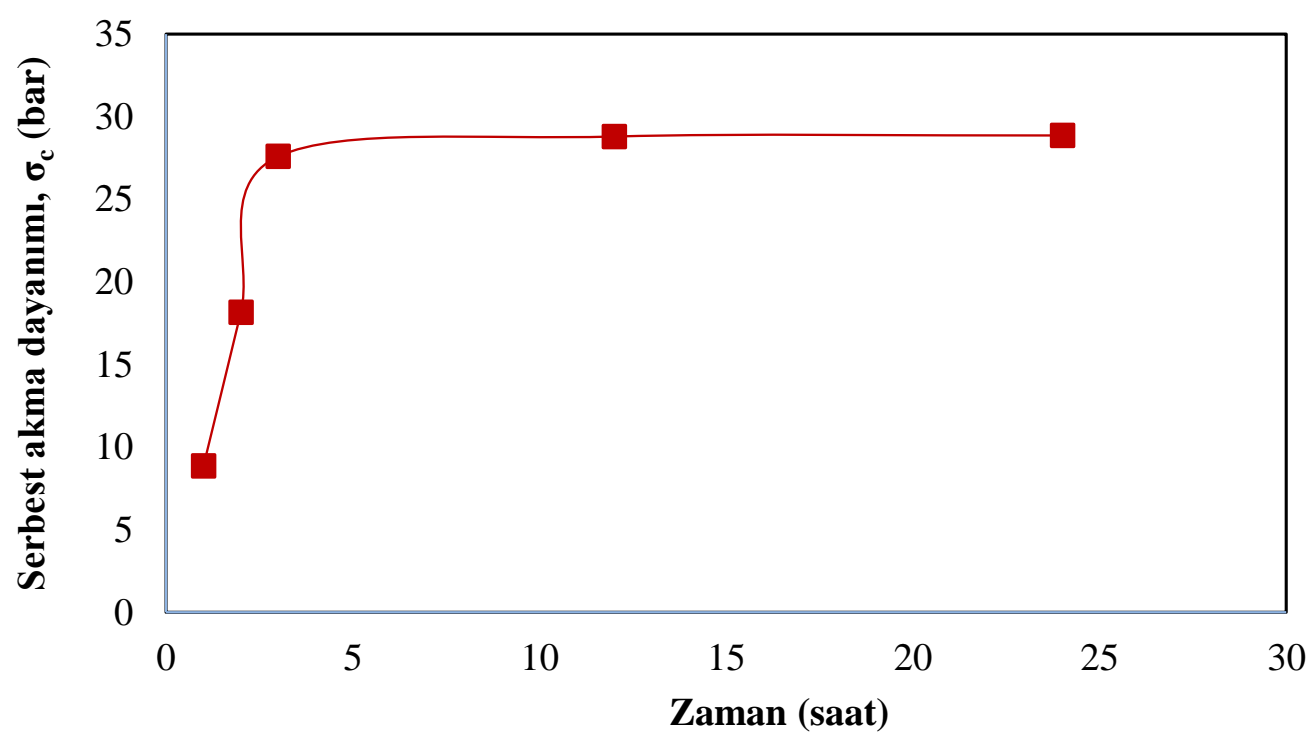

Şekil 9. CMSMPR tipi kristalizörde, saf ortamda üretilen $\mathrm{Na}_{2} \mathrm{~B}_{4} \mathrm{O}_{7} .5 \mathrm{H}_{2} \mathrm{O}$ kristallerine 50 bar sıkıştırma basıncı $\left(\sigma_{1}\right)$ uygulanması durumunda farklı zamanlar için serbest akma dayanımının değişimi

Tablo 7. $\mathrm{Na}_{2} \mathrm{~B}_{4} \mathrm{O}_{7} .5 \mathrm{H}_{2} \mathrm{O}$ kristalleri için sıkıştırma basıncının serbest akma basıncına oranı olan sabit akıcılık doğrusu $\left(\mathrm{ff}_{\mathrm{c}}\right.$ ) sonuçları

\begin{tabular}{ccc}
\hline $\begin{array}{c}\text { Sıkıştırma basınc1, } \\
\sigma_{1}(\text { bar })\end{array}$ & $\begin{array}{c}\text { Serbest akma dayanımı, } \\
\sigma_{\mathrm{c}}(\text { bar })\end{array}$ & $\begin{array}{c}\mathrm{ff}_{\mathrm{c}} \\
\left(\sigma_{1} / \sigma_{\mathrm{c}}\right)\end{array}$ \\
\hline 0 & 0 & 0 \\
30 & 16.321 & 1.838 \\
40 & 22.156 & 1.805 \\
50 & 27.589 & 1.812 \\
60 & 32.475 & 1.847 \\
70 & 38.365 & 1.825 \\
\hline
\end{tabular}




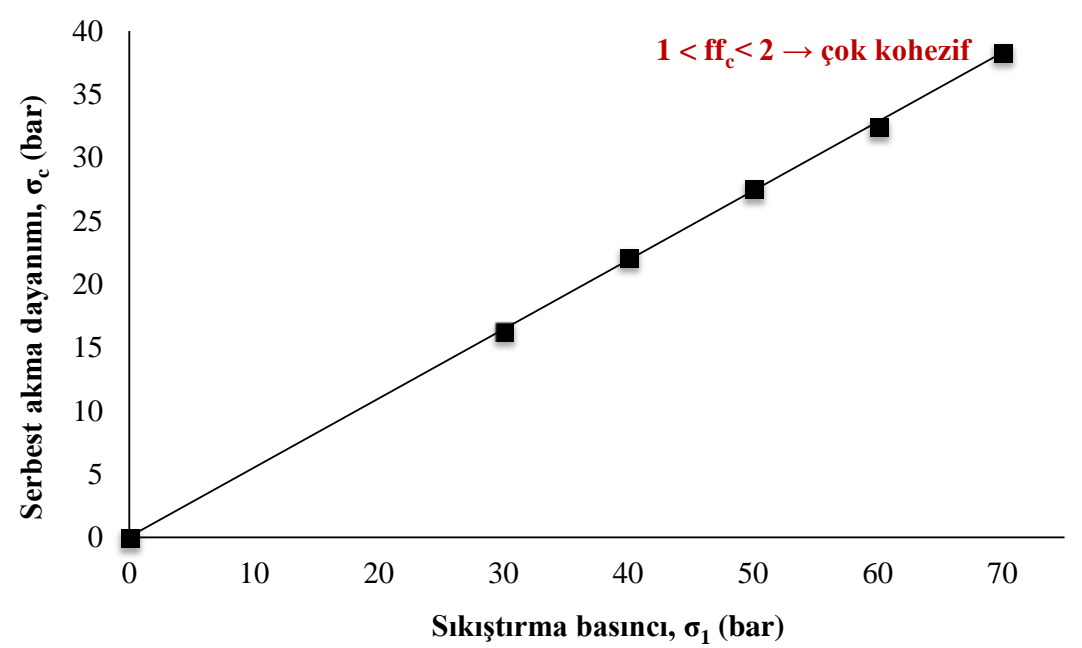

Şekil 10. Saf ortamda üretilen $\mathrm{Na}_{2} \mathrm{~B}_{4} \mathrm{O}_{7} .5 \mathrm{H}_{2} \mathrm{O}$ kristallerinin sabit akıcılık doğrusu, $\mathrm{ff}_{\mathrm{c}}$

\section{Sonuç ve Öneriler}

$\mathrm{Bu}$ çalışmada, sürekli-karıştırmalı, sürekli-ürün çekmeli CMSMPR tipi kristalizörde, saf ortamda üretilen $\mathrm{H}_{3} \mathrm{BO}_{3}$ ve $\mathrm{Na}_{2} \mathrm{~B}_{4} \mathrm{O}_{7} .5 \mathrm{H}_{2} \mathrm{O}$ kristallerinin su alma yeteneği, kekleşme derecesi tayini ve mekanik dayanım, kekleşme, kırma testleri yapılmıştır. CMSMPR sisteminde üretilen hem $\mathrm{H}_{3} \mathrm{BO}_{3}$ hem de $\mathrm{Na}_{2} \mathrm{~B}_{4} \mathrm{O}_{7} .5 \mathrm{H}_{2} \mathrm{O}$ kristallerinin su alma yeteneği, kekleşme, aşınma derecelerinin yüksek olduğu ve bu kristallerin nemden oldukça etkilendiği dolayısıyla habitinde bozulmalar meydana geldiği görülmüştür. Bununla birlikte, $\mathrm{H}_{3} \mathrm{BO}_{3}$ kristallerinin su alma yeteneği ve kekleşme derecesi $\mathrm{Na}_{2} \mathrm{~B}_{4} \mathrm{O}_{7} .5 \mathrm{H}_{2} \mathrm{O}$ kristallerine nazaran daha düşük, aşınma derecesinin ise daha yüksek olduğu bulunmuştur. Ayrıca, kekleşme ve kırma testleri sonucunda belirlenen akışkanlık durumları değerlendirildiğinde ise, saf ortamda üretilen $\mathrm{H}_{3} \mathrm{BO}_{3}$ kristallerinin kohezif (yapışan), $\mathrm{Na}_{2} \mathrm{~B}_{4} \mathrm{O}_{7} .5 \mathrm{H}_{2} \mathrm{O}$ kristallerinin ise çok kohezif olduğu tespit edilmiştir. Tüm bu sonuçlar esas alındığında, kekleşmeyi önlemek için $\mathrm{H}_{3} \mathrm{BO}_{3}$ ve $\mathrm{Na}_{2} \mathrm{~B}_{4} \mathrm{O}_{7} .5 \mathrm{H}_{2} \mathrm{O}$ kristallerinin yüksek nem oranlarına maruz kalmaması gerektiği görülmektedir. Çalışma kapsamında yapılan testler esas alındığında, kekleşme eğilimini önlemek için $\mathrm{H}_{3} \mathrm{BO}_{3}$ ve $\mathrm{Na}_{2} \mathrm{~B}_{4} \mathrm{O}_{7} .5 \mathrm{H}_{2} \mathrm{O}$ kristalleri için uygun kalite özellikleri belirlenmiş ve özellikle endüstriyel olarak üretilen bor ürün kristallerinde görülebilecek kekleşme eğiliminin tespiti ile ilgili önemli bir eksiklik giderilmiştir. Literatürde, $\mathrm{H}_{3} \mathrm{BO}_{3}$ ve $\mathrm{Na}_{2} \mathrm{~B}_{4} \mathrm{O}_{7} .5 \mathrm{H}_{2} \mathrm{O}$ kristalleri için su alma yeteneği, kekleşme derecesi tayini ve mekanik dayanım, kekleşme, kırma testlerinin yapılmasına yönelik herhangi bir çalışmaya rastlanmamış ve ilk defa yapılan bu çalışma ile araştırmacılara ve literatüre önemli katkılar sunulmuştur.

\section{Yazarların Katkısı}

Sinan Kutluay: kavramsallaştırma, araştırma, görselleştirme, yazma-inceleme ve düzenleme. M. Sait İzgi: inceleme. Ömer Şahin: denetim, gözden geçirme ve araştırma. A. Abdullah Ceyhan: denetim, gözden geçirme ve araştırma.

\section{Çıkar Çatışması Beyanı}

Yazarlar arasında herhangi bir çıkar çatışması bulunmamaktadır.

\section{Araştırma ve Yayın Etiği Beyanı}

Yapılan çalışmada, araştırma ve yayın etiğine uyulmuştur.

\section{Kaynaklar}

[1] Etimaden, 2016. Bor sektör raporu. Ankara, 5-16. 
[2] Kutluay S., Şahin Ö., Ceyhan A.A., İzgi M.S. 2017. Design and Optimization of Production Parameters for Boric Acid Crystals with the Crystallization Process in an MSMPR Crystallizer using FBRM ${ }^{\circledR}$ and PVM ${ }^{\circledR}$ Technologies. Journal of Crystal Growth, 467 (1): 172-180.

[3] Kutluay S., Ceyhan A.A., Şahin Ö., İzgi M.S. 2020. Utilization of In Situ FBRM and PVM Probes to Analyze the Influences of Monopropylene Glycol and Oleic Acid as Novel Additives on the Properties of Boric Acid Crystals. Industrial \& Engineering Chemistry Research, 59 (19): 191989206.

[4] Schmitt L.C. 1963. Production of a Non-Caking Borax. U.S.A patent No. 3, 109, 705.

[5] Fitzpatrick J.J., Hodnett M, Twomey M, Cerqueira P.S.M., O'Flynn J, Roos Y.H. 2007. Glass Transition and the Flowability and Caking of Powders Containing Amorphous Lactose. Powder Technology, 178 (2): 119-128.

[6] Mullin J.W. 2001. Crystallization. Butterworth-Heinemann, London.

[7] Subaşı N. 2014. Boraks Dekahidratın Kekleşmesinin Önlenmesi. Yüksek Lisans Tezi, İstanbul Teknik Üniversitesi, Fen Bilimleri Enstitüsü, İstanbul.

[8] Göcen Ü. 2010. Boraks Dekahidratın Kristalizasyon Özelliklerinin İncelenmesi. Yüksek Lisans Tezi, İstanbul Teknik Üniversitesi, Fen Bilimleri Enstitüsü, İstanbul.

[9] Cleaver J.A.S., Karatzas G, Louis S, Hayati I. 2004. Moisture-Induced Caking of Boric Acid Powder. Powder Technology, 146 (1): 93-101.

[10] GEA. 2016. Analytical Methods Dry Milk Products. GEA Niro Analytical Methods, Method A 14a-Hygroscopicity Soeborg: GEA Niro Research Laborator, [Available from: http://www.gea.com/en/binaries/A\%2014\%20a\%20-\%20Hygroscopicity_tcm11-30922.pdf (Erişim tarihi: 15.03.2017).

[11] GEA. 2016. Analytical Methods Dry Milk Products. GEA Niro Analytical Methods, Method A 15a-Degree of Caking Soeborg: GEA Niro Research Laborator, [Available from: http://www.gea.com/en/binaries/A\%2015\%20a\%20-\%20Degree\%20of\%20Caking_tcm1130923.pdf (Erişim tarihi: 20.02.2017).

[12] GEA. 2016. Analytical Methods Dry Milk Products. GEA Niro Analytical Methods, Method A 1c-Free Moisture Soeborg: GEA Niro Research Laborator, [Available from: http://www.gea.com/en/binaries/A\%201\%20c\%20-\%20Free\%20Moisture_tcm11-30902.pdf (Erişim tarihi: 28.02.2017).

[13] Myerson A.S. 1981. Determination of Degree of Attrition of Sodium Perborates. Handbook of Industrial Crystallization, British Standards Institution, 1-5688.

[14] Schulze D. 2001. Flow Properties of Powders and Bulk Solids and Silo Design for Flow. Produktbroschüre, Internationaler Kongress für Partikeltechnologie Powtech, 27-29 March, Partec Nürnberg. 